\title{
La Censura de Félix Restrepo AL TÍTULO DE LA MALA HORA: UNA CONTIENDA GLOTOPOLÍTICA ENTRE EL FASCISMO Y LA LETRA*
}

\author{
Félix Restrepo's Censorship of the \\ Title of IN EVIL HouR: A Glottopolitical \\ Battle Between Fascism and Literature
}

Carolina Chaves O'Flynn ${ }^{1}$

\footnotetext{
* Cómo citar este artículo: Chaves O’Flynn, C. (2021). La censura de Félix Restrepo al título de La mala hora: una contienda glotopolítica entre el fascismo y la letra. Estudios de Literatura Colombiana 49, pp. 53-69. DOI: https://doi.org/10.17533/udea.elc.n49a03

1 https://orcid.org/0000-0001-7851-3760 cchaves@qcc.cuny.edu Queensborough Community College (City College of New York, cunY), United States.
}

Editores: Andrés Vergara Aguirre, Christian Benavides Martínez

Recibido: 15.02 .2021

Aprobado: 21.05.2021

Publicado: 30.06 .2021

Copyright: (2021 Estudios de Literatura Colombiana. Este es un artículo de acceso abierto distribuido bajo los términos de la Licencia Creative Commons AtribuciónNo comercial-Compartir igual 4.0 Internacional
Resumen: Este artículo examina la autoridad lingüística del reverendo Félix Restrepo durante el siglo xx colombiano y la influencia del franquismo, a través del ejercicio de censura del Instituto Nacional del Libro Español (INLE), en la literatura colombiana del siglo xx. Concretamente, el texto recoge un episodio de intervención lingüística en el campo literario colombiano, relacionado con el cambio de nombre de la novela $L a$ mala hora de García Márquez en 1962. El campo de reflexión es el de la sociolingüística crítica con perspectiva glotopolítica, que precisa la atención a las relaciones de poder y dominio ancladas en el contexto político específico en el que se produce la disputa lingüística.

Palabras clave: glotopolítica; Colombia; Félix Restrepo; La mala hora; Gabriel García Márquez.

Abstract: This article explores Reverend Felix Restrepo's linguistic authority during the Colombian twentieth century and Francoism's influence through the censorship of the Spanish National Book Institute (INLE) on Colombian literature of the twentieth century. Specifically, the text covers an episode of linguistic intervention in the Colombian literary field, related to the change of name of García Márquez's novel In Evil Hour in 1962. The reflection area is critical sociolinguistics with a glotopolitical perspective, which requires attention to the relations of power and domination anchored in the specific political context in which the linguistic dispute occurs.

Keywords: glottopolitics; Colombia; Félix Restrepo; In Evil Hour; Gabriel García Márquez. 
Antes de ustedes, este era un pueblo de mierda, como todos, pero ahora es el peor de todos.

Before you all, this was a shitty town, like all others, but now it is the worst of all.

In Evil Hour

\section{Introducción}

Cuenta García Márquez en Vivir para contarla (2002) que en 1962, tras ser galardonado con el Premio Esso de novela (1961), recibió una carta del entonces presidente de la Academia Colombiana de la Lengua, el reverendo jesuita Félix Restrepo (1887-1965), quien había presidido el jurado del concurso que premió a García Márquez. Incluso hasta después de la premiación, se desconocía el nombre de la novela ganadora porque, según el escritor, dada la premura de la entrega, había olvidado ponerlo en el manuscrito que envió al concurso. El título original de la novela, "Este pueblo de mierda", escandalizó al jesuita, quien le pidió a través de German Vargas Cantillo que lo cambiara por "uno menos brutal y más a tono con el tema del libro". ${ }^{1}$ Hecho sobre el que García Márquez (2002) comenta: "Al cabo de muchos intercambios con él, me decidí por un título que tal vez no dijera mucho del drama pero que le serviría de bandera para navegar por los mares de la mojigatería: La mala hora" (p. 272). Restrepo también le invitaba a eliminar de la novela "unos pocos brochazos obscenos" (Jaramillo, 2012, párr. 10) advertidos durante su lectura. Después de tomarse el tiempo suficiente para "meditar sobre los comentarios" y luego de una nueva lectura de su novela, el escritor le respondió a Restrepo con otra carta firmada el 22 de mayo de 1962:

Mi novela revela, primordialmente, una preocupación: la existencia y predominio de una falsa moral religiosa, familiar, política, económica y social, en lugares que se suponen civilizados y cultos. Para plantear esa preocupación en términos convincentes era preciso tratar de descuartizar sin piedad la realidad aparente, y descender al subsuelo de los instintos, con graves riesgos de comprometer la dignidad literaria de la novela (párr. I3).

Poco después, Carlos Arango Vélez, embajador de Colombia en México, le informó a García Márquez que el clérigo Restrepo suplicaba ahora el cambio de dos pala-

1 Vargas Cantillo fue un importante periodista y escritor barranquillero. Trabajó en varios periódicos y para varias administraciones presidenciales. Se le conocía como un "descubridor de talentos" porque "bajo su cuidado" en el periódico El Heraldo pasaron casi todos los escritores de la Costa Atlántica, hoy reconocidos mundialmente (véase: https://www.eltiempo.com/archivo/documento/MAM-88195). 
bras más que le parecían “inadmisibles” en la novela premiada, a saber: "preservativo" y "masturbación”. Puesto que el concurso consistía en publicar en Madrid la novela ganadora, el Nobel accedió a eliminar solo una de las dos entradas - a escogencia del embajador - y, así, el libro se imprimió en la editorial Iberoamericana de Madrid sin el vocablo “masturbación” entre sus depuradas líneas castellanas. Sin embargo, García Márquez (2002) expresa que "fue una luna de miel efímera, porque no pude resistir la tentación de hacer una lectura exploratoria, y descubrí que el libro escrito en mi lengua de indio había sido doblado [...] al más puro dialecto de Madrid” (p. 272). En 1963 a través de una carta pública, divulgada por el diario El Espectador, el autor desautorizó la edición por considerarla “adulterada”, e hizo eliminar los ejemplares que aún no se hubieran vendido. Tuvo además que "retraducir" a su "dialecto caribe" la versión española "malformada” porque la única copia original era la que se había mandado al concurso, es decir, la misma que se había ido a España para la edición. "Una vez restablecido el texto original [la novela fue publicada] por la editorial Era de México, con la advertencia impresa de que era esa la primera edición” de la novela de García Márquez (García Márquez, 2002, p. 273). La edición de La mala hora publicada en México en 1966 abre su contraportada con la siguiente nota:

La primera vez que se publicó La mala hora, en 1962, un corrector de pruebas se permitió cambiar ciertos términos y almidonar el estilo, en nombre de la pureza del lenguaje. En esta ocasión, a su vez el autor se ha permitido restituir las incorrecciones idiomáticas y las barbaridades estilísticas, en nombre de su soberana y arbitraria voluntad. Esta es, pues, la primera edición de La mala hora. eL AuTor (García Márquez, 1966).

Ante la molestia de García Márquez por el "doblaje” de su novela, el sacerdote Félix Restrepo contactó al Instituto Nacional del Libro Español (INLE), ${ }^{2}$ responsable de la edición de la obra, para transmitir la denuncia del autor. En su misiva, Restrepo sugirió la conveniencia de que las futuras obras de autores colombianos no fueran editadas en España para evitar así “adulteraciones” de los “textos originales”. La casa editorial, a través de su entonces presidente Carlos Robles Piquer, se disculpó con

2 El INLE fue creado en 1939 por el Ministerio de la Gobernación de Francisco Franco. El Instituto inició labores solo hasta 1941 una vez su reglamento fue aprobado como cuerpo consultivo. Su propósito inicial, fuertemente ejercido durante la década de los años cuarenta, fue tanto vigilar y censurar la industria editorial española como controlar las políticas locales relacionadas con el libro, siempre en favor de la moralidad, la disciplina y los ideales políticos propugnados por el franquismo. 
Restrepo arguyendo un "error involuntario" cometido por el "excesivo purismo" del corrector. Esto, no sin antes reiterar que, hasta aquel particular, las obras de otros autores latinoamericanos se realizaron siempre "sin incidentes" y con la "plena satisfacción" de sus autores, y ofrecer publicar la novela conforme su versión original (Jaramillo, 2012, párr. 25). Por entonces, los oficiales franquistas de alto rango le temían tanto a la amenaza de la industria editorial cubana como a la producción norteamericana, que amenazaba con arrebatar a España el control geocultural sobre América Latina (Santana-Acuña, 2020, p. 29).

Fueron varias las oportunidades en que García Márquez manifestó su inconformismo frente a las normativas de las Academias. En diversas notas de prensa (1980-1984), el escritor cuestionó "la pretendida autoridad que tienen las academias para indicar a los hablantes cuándo están utilizando una palabra de manera correcta o incorrecta" (Cabello Pino, 2020, p. 479). También fue profuso en delatar su obsesión por los diccionarios e insistir en que el de María Moliner, lexicógrafa nunca agregada a la Real Academia Española (RAE), fue “el más completo, más útil, más acucioso y más divertido de la lengua castellana [...] dos veces más largo que el de la Real Academia de la Lengua, y [...] más de dos veces mejor”. Muchos diccionarios posteriores, no serían para él más que copias del que Moliner hubiera confeccionado años antes (Cabello Pino, 2019, p. 448). Pero, sin duda, el episodio más arrojado de García Márquez hacia la RAE fue su ponencia "Botella al mar para el dios de las palabras”, que profirió con motivo de la apertura del Congreso Internacional de la Lengua Española (ciLE) de Zacatecas (1997), donde propuso "simplificar la gramática y humanizar sus leyes" a través de una propuesta ortográfica que causó revuelo entre los asistentes "y el consiguiente malestar de la intelectualidad (ejemplos son Juan Goytisolo, Octavio Paz, Antonio Gala o Francisco Umbral) y las autoridades académicas" (Sánchez García y Jiménez Mañas, 2012, p. 5).

Sirva la anécdota de La mala hora para dar cuenta del caudal político del reverendo jesuita Félix Restrepo, de su devoción por los valores conservadores de herencia colonial y, en últimas, de su capacidad de dominio del campo literario colombiano. Sirva también para ilustrar la crecientemente conseguida autoridad literaria de García Márquez, quien para los años sesenta ya puede permitirse "hablar" y "escribir" como le dicta su "soberana y arbitraria voluntad", puestas las protecciones de su consagración como autor dentro del campo literario colombiano. Este pasaje de La mala 
hora también deja ver las tensiones existentes en el plano cultural que rodearon el tema de la pureza de la lengua a mediados del siglo xx en Colombia, la influencia de políticos y editores colombianos y españoles en el mundo literario nacional, y la supremacía de la Academia de la Lengua en medio de estas disputas e intercambios culturales. Estimar que García Márquez venció en la batalla lingüística propiciada por su novela con la publicación de una edición alternativa de La mala hora es tal vez una presunción inexacta y apresurada. A fin de cuentas, el libro se publicó como $L a$ mala hora y del título original, "Este pueblo de mierda", no queda más que el entretenido recuerdo. Lo que es más, algo en la irreverencia literaria de García Márquez parece haberse extenuado con el transcurso del tiempo y a fuerza de reparos editoriales de todo tipo (Santana-Acuña, 2020, p. 86). Por dar tan solo una pista de ello, tras el decreto de una nueva Ley de prensa impuesta en España en 1966, los censores españoles juzgaron con beneplácito que la novela cumbre de García Márquez, Cien años de soledad, no contuviera una jerga criolla, que fuera preciso corregir y usar, en cambio, un castellano clásico propio de la variante estándar peninsular (p. 71). Esto pudo significar, o bien que los censores españoles de los años sesenta ya habían flexibilizado largamente sus severidades editoriales, o bien que García Márquez optó también por autocensurar su propio estilo narrativo, en aras de evitar nuevos imprevistos como los que antecedieron a los Cien años de soledad.

Esta duda persiste, sin embargo, a partir de la edición de Cien Años de Soledad, publicada por la RAE, la Asociación de Academias de la Lengua Española (ASALE) y la editorial Alfaguara, en el año 2007, con motivo del octogésimo cumpleaños del Nobel y presentada en el marco del IV Congreso Internacional de la Lengua Española en Cartagena de Indias. Ya desde la contraportada de la mentada edición, se advierte que el texto fue "revisado [por] el propio Gabriel García Márquez" (García Márquez, 2007, p. 2), no sin también mencionar - con un cierto disimulo suavizador- los previos forcejeos que pudieran haberse presentado entre el autor y otros editores anteriores:

A pesar del esmero con que el propio escritor corrigió las pruebas de la primera edición (Sudamericana, 1967), se deslizaron en ella indeseadas erratas y expresiones dudosas que editores sucesivos han tratado de resolver con mejor o peor fortuna. Un estudio comparativo detallado de cada caso ha permitido ahora presentar una propuesta razonada al propio autor, que ha querido revisar las pruebas de imprenta completas, enriqueciendo así esta edición con su trabajo de depuración y fijación del texto (p. 2). 
La "Nota al texto", por lo demás, reitera continuamente la autónoma decisión del escritor en realizar toda suerte de enmiendas, que a su vez arrojaron "algunas pistas sobre la decidida intención de García Márquez de seguir la norma literaria [pues fue él mismo quien modificó] en algunos lugares del texto la puntuación, y la acentuación [fue] normalizada" (p. 8). Voluntaria o no, la corrección de la versión original de la novela cumbre de la literatura colombiana fue estimulada desde las instituciones que se precian de su ejercicio de custodia de la lengua y su invitación conmemorativa a publicar la novela significó, sin lugar a dudas, una "depurada" alteración.

Por último, y volviendo al episodio de La mala hora, es claro que su historia exhibe la autoridad lingüística del jesuita Félix Restrepo en la práctica cultural colombiana, y los hábitos de corrección y obediencia que orbitan sobre las representaciones de la lengua española en Colombia. Entre los rastros ocasionales que deja el imprevisto, puede observase que, de los agentes partícipes del episodio, únicamente García Márquez levanta una genuina voz opositora al proceso ideológico de censura editorial impuesto desde España y auspiciado por la Iglesia católica y la Academia Colombiana de la Lengua. Con todo, el escritor modifica su novela en aspectos bastante significativos con el propósito de evitar más trabas editoriales tanto en la consecución del Premio Esso como en el proceso de publicación de su novela. Es precisamente en la construcción y la proyección de una autoridad lingüística en el campo cultural colombiano que indagará este trabajo, a partir de una perspectiva crítica que atienda a los contextos políticos sobre los que emergen los discursos acerca de la lengua española en Colombia. En otras palabras, este trabajo asume como punto de partida una postura crítica con perspectiva glotopolítica para la lectura de los acontecimientos extralingüísticos que rodean el cambio de título de la novela La mala hora.

\section{La dimensión glotopolítica}

La glotopolítica puede entenderse como "un espacio disciplinario definido por una concepción fundamentalmente contextual del lenguaje [que] afirma, obviamente, un interés por las dimensiones del fenómeno (del lenguaje) que se manifiestan (y por lo tanto se han de interpretar) en el terreno de lo político" (Del Valle, 2007, p. 14). Vista así, la glotopolítica, una perspectiva crítica, posibilita la reflexión sobre las re- 
presentaciones simbólicas de la lengua de acuerdo con el contexto político en el que afloran los discursos sobre ella. Esto implica una revisión de las relaciones de poder específicas que se entretejen en torno al control simbólico de la lengua. En este sentido, el prisma glotopolítico invita a percatarse de esa dimensión política de la lengua, a la luz de categorías como poder, legitimidad y autoridad, que tienden a naturalizar ordenamientos y prácticas de tipo cultural, político y social entre los hablantes de una comunidad (p. 14). Por dar tan solo un ejemplo, tras la fachada de atesoramiento institucional panhispanista de una lengua común, abanderada desde la península ibérica a la cabeza de la RAE, se ha ejercido control de legitimidad y dominio sobre la lengua española, a fuerza de la vigilancia y control de sus hablantes. La autoridad normativa que edifica la RAE a través de sus academias, diccionarios y gramáticas le concede legitimidad entre los hablantes, quienes a su vez tienden a privilegiar una forma del "hablar bien" una "lengua oficial", que las más de las veces se corresponde con el habla de aquellos que dominan las esferas de poder (De Arnoux y Del Valle, 2010, p. 16; Del Valle, 2007, p. 175). Por lo demás, "el valor de la lengua oficial se deriva del poder del Estado para recompensar a quienes la conocen y sancionar a quienes la ignoran" (De Arnoux y Del Valle, 2010, p. 3); por lo que hay tanto quienes se benefician como quienes se ven perjudicados por cuenta de las jerarquías derivadas de unas maneras de hablar que, en este orden ideológico, resultan superiores a otras. En este marco de análisis, "el lenguaje mismo, en tanto que acción política, exige ser definido como fenómeno ideológico-discursivo, es decir, como entidad dinámica en constante relación dialógica con el contexto" (Del Valle, 2007, p. 14). De allí que entre los miembros de una comunidad de hablantes, en la que se intercambian prácticas discursivas de carácter simbólico, abunden ideas asimiladas acríticamente con respecto al dominio de una norma lingüística; es decir, es usual que se compartan pródigamente ideologías lingüisticas entre los hablantes de una lengua común (Del Valle, 2007, p. 175; De Arnoux y Del Valle, 2010, p. 17). En este orden, el episodio garciamarquiano de La mala hora es, a todas luces, un suceso glotopolítico. La autoridad axiomática de las instituciones vigías de la lengua y la obediencia naturalizada de los hablantes en el contexto cultural colombiano están sujetas a un complejo armazón político que se remonta, a lo menos, a los inicios de la dictadura de Francisco Franco en España y al brote de las luchas bipartidistas, mediadas por la Iglesia católica, que abonaron el terreno de disputa para la época de la Violencia en Colombia. 


\section{Entramado histórico}

Poco antes de finalizada la Guerra Civil española (1936-1939), se redactó la Ley de prensa de 1938, proclama que supuso la extensa imposición de una censura previa y el nombramiento o despido de directores de prensa por disposición del Estado, conforme resultaran aliados o contradictores del régimen. Ni la censura previa ni las leyes de prensa constituían una novedad en España, que "contó en repetidas ocasiones con iniciativas legislativas encaminadas a censurar el trabajo de los periodistas" (Mesa, 2005, párr. 1), como las Leyes de imprenta de 1879 y 1883; sin embargo, la de 1938 fue una ley bastante más implacable con las voces antagonistas al gobierno de turno y la centralización de la información en favor del régimen franquista y las instituciones afines a él. "Además de las informaciones, el régimen de Franco intenta controlar a los profesionales del periodismo. En 1941 se crea la Escuela Oficial de Periodistas, en la que es imprescindible ser militante de la Falange Española y de las jons para ingresar" (párr. 44). La censura asediaba todo atisbo de comunismo y liberalismo, realzando por lo demás el nacionalismo, el conservadurismo y la religión católica, sólidamente encarnadas por la Falange (Chuliá, 1999, p. 203; Mesa, 2005, párr. 9, 31-34).

A la vuelta de los años, luego de la Segunda Guerra Mundial y la derrota de regímenes fascistas por parte de los Aliados, España se encontró en un estado de enorme aislamiento mundial y bajo una fuerte presión internacional por cuenta de las economías planetarias imperantes, que veían con muy malos ojos la cercanía de la Falange con la dictadura nazi. Para favor de Franco, la Guerra Fría significó el olvido de sus filiaciones fascistas ante las potencias capitalistas en enfrentamiento con la Unión Soviética, y su reivindicación ante las democracias de Occidente como un estandarte anticomunista en medio del Mediterráneo. En aras de desmarcarse de la imagen del fascismo, Franco hizo un reajuste ministerial entre los que contaba con Manuel Fraga como ministro de Información y Turismo, quien proclamó la Ley de Prensa de 1966, que flexibilizaba la censura previa y derogaba varios de los artículos prohibitorios de su versión anterior. Limpiar la imagen del régimen franquista precisó también proyectar una imagen de apertura internacional y una agenda de reivindicación cultural hacia el exterior, con interesantes repercusiones para América Latina. Para ello, se acudió a las instancias conservadoras y católicas latinoamericanas en aras de buscar apoyo en lo que constituyó una política cultu- 
ral, a través de la producción editorial ultramarina (Santana-Acuña, 2020, p. 200; Chuliá, 1999, pp. 204-208; Mesa, 2005, párr. 39).

Como apunta Santana-Acuña (2020), durante gran parte de la segunda mitad del siglo xx, la empresa editorial española estuvo muy por encima de la mexicana y argentina, sus dos competidores principales en el ámbito de la publicación de literatura propiamente latinoamericana. Sin embargo, España llegó a sentir amenazada su ventaja en el mercado latinoamericano, hecho que también influyó, aunque en menor medida, en la puesta en vigencia de la Ley de 1966. Los censores, entre los que había curas, abogados y estudiantes, influenciaron estéticamente la literatura latinoamericana que pasó por sus manos en la revisión de la lengua y el estilo. Al tiempo que celebraron a Borges por su español clásico y erudito en Dreamtigers, los censores españoles rechazaron la publicación de Sobre héroes y tumbas de Ernesto Sábato y $\mathrm{La}$ región más transparente de Carlos Fuentes, dada la "abundancia de dichos" "lenguaje incomprensible” entre sus páginas (Santana-Acuña, 2020, pp. 49-51). El caso que aquí nos concierne, el de La mala hora de García Márquez, es resultado directo tanto de las severas dinámicas de censura cuanto de la preocupación del gobierno español por perder consumidores en el mercado latinoamericano, por cuenta de los tropiezos impuestos por sus propias pautas editoriales (pp. 49-50).

Entre tanto, al otro lado del Atlántico, y pese a que en Colombia gobernaba después de muchos años un gobierno liberal, los idearios hispánicos y fascistas del franquismo penetraban las instancias culturales y estatales colombianas, a través de la acción política del Partido Conservador y la Iglesia católica. La prensa tradicional reportaba el conflicto de la guerra civil española como si se tratara de un reflejo del conflicto interno colombiano, dada la similitud en los altercados políticos, la intolerancia ideológica entre los partidos Liberal y Conservador, y las manifestaciones de violencia entre sus huestes (Hernández García, 2006, pp. 31-68; Gaitán-Bohórques y Malagón Pinzón, 2009, pp. 302-304). Al tal punto se asociaron los problemas domésticos de cada país, que por lo general se asoció a los sectores liberales con los militantes republicanos y a las facciones conservadoras con los partidarios del franquismo. Más diciente aún fue el hecho de que las juventudes de derecha colombianas imitaron la militancia de aquellas organizaciones juveniles españolas "que intervenían en España: La Falange, los requetés, carlistas, los mendigozales y las J.A.P.” (Ayala Diago, 2011, p. 119), y por todas partes pulularon los movimientos con inclinaciones fascistas: 
El año 1936 fue el de proliferación de los grupos falangistas. El Tiempo de Bogotá anunció en enero la creación de una agrupación fascista llamada "Haz de fuego" y la designación de la jefatura hecha por los falangistas del centro "Primo de Rivera". En las universidades bogotanas se formaron grupos fascistas. En Medellín apareció una organización militar denominada "La Cruz de Malta" y otra agrupación con carácter claramente fascista denominada "Haz de Juventudes Godas". Al amparo del "Haz Godo de Antioquia" se crearon varias falanges de universitarios, obreros, "retaguardia de niños" y una falange de mujeres (Gaitán-Bohórques y Malagón Pinzón, 2009, p. 304).

Por lo demás, la pugna política se desplazó al plano del hispanismo defendido con arrojo por el pensamiento tradicionalista y conservador colombiano, mancomunado con una mirada de España como guía espiritual y lingüística del país. La religión católica y la lengua eran erarios indiscutibles del pasado colonial colombiano, que habrían de protegerse a través del control de la educación por cuenta de la Iglesia católica. “En Colombia se invocaba el 'hispanismo renaciente' y 'salvador', cuyo triunfo falangista significaba la reacción triunfante de las fuerzas conservadoras tradicionales contra la 'diabólica revolución marxista' y el liberalismo, 'ese liberalismo infectado de marxismo que conduce fatalmente al comunismo"' (Gaitán-Bohórques y Malagón Pinzón, 2009, p. 302). Con todo, la extendida influencia del clero en los asuntos de enseñanza y Estado desde tiempos coloniales encontró varios obstáculos en las reformas liberales planteadas durante la República Liberal (1930-1948) en Colombia. No está de más recordar que la Constitución de 1886, impulsada por el movimiento de la Regeneración e instituida durante el periodo denominado la Hegemonía conservadora (1886-1930), declaraba a Colombia como una nación monolingüe y católica. Esta carta ultraconservadora sería desafiada por los gobiernos liberales de los años treinta, que buscaban modernizar la política, la educación y la economía colombianas. Ello suponía, entre otras reformas, la libertad de cultos y de conciencia, la organización sindical, el sufragio universal y la oficialización de la educación laica.

Entre las resistencias provocadas por estas reformas, la Iglesia colombiana profranquista propuso inclusive un régimen económico como la salida política y social a los conflictos internos que acosaban al país. Se trató de un Corporativismo de corte clerical, que perseguía como principio fundamental la consecución de un bien común, bajo la guarda todopoderosa de Dios, y al cuidado de la Iglesia católica a través de un recobrado control sobre la educación nacional (Figueroa Salamanca y Tuta Alarcón, 2005, pp. 115-127; Gaitán-Bohórques y Malagón Pinzón, 2009, p. 308; Ayala Diego, 2011, p. 117). 
En la base del movimiento corporativista colombiano puede identificarse un rasgo común señalado por Hobsbawm para los movimientos de este tipo, como lo fue la nostalgia ideológica por una edad media o por una sociedad feudal imaginadas en las que se reconocía la existencia de clases o grupos económicos, pero que conjuraba el peligro de la lucha de clases mediante la aceptación de la jerarquía social, y el reconocimiento de que cada grupo social o "estamento" desempeñaba una función social orgánica (Gaitán-Bohórques y Malagón Pinzón, 2009, p. 308).

Uno de los más temerarios defensores del proyecto económico corporativista en Colombia fue el sacerdote jesuita Félix Restrepo. El corporativismo confesional de Restrepo profesaba las profesiones como determinantes justas de las jerarquías sociales y la propiedad privada en tanto derecho sustancial a determinados sectores sociales. "Lo justificaba como una opción diferente al liberalismo individualista y a la lucha de clases, haciendo prevalecer el bien común, como un 'derecho natural"' (Figueroa Salamanca y Tuta Alarcón, 2005, p. 129). Por lo demás, Félix Restrepo acariciaba una utopía para Colombia, a la que llamaría Cristilandia, y que consistía en convertir a Colombia en una comarca donde reinara la ley de Cristo bajo la “íntima colaboración entre la Iglesia y el Estado", pues únicamente "la unión de las dos potestades Iglesia y Estado, para encauzar las actividades de los ciudadanos superará el egoísmo y generará la cooperación” (Henríquez de Hernández, 1989, p. 87). Como se lee, la copiosa actividad cultural de Restrepo, durante la primera mitad del siglo xx en Colombia, tuvo como principios rectores la recuperación del control de la educación para la Iglesia y la custodia de la lengua española, y no fue nunca ajena al orden político interno y transnacional. Antes bien, Félix Restrepo fue un asiduo defensor del franquismo, condenador de huestes comunistas y afianzador de las lógicas autoritarias asociadas al control de la lengua. En sus propias palabras, consignadas en el texto España mártir de 1936, expresaba así su opinión sobre la Segunda República española:

La política revolucionaria española desde la instauración de la república fue siempre conducida por anormales. Es este un hecho digno de ser esclarecido por los psicólogos; pero la revolución comunista ha llevado a los primeros y segundos planos de sus actividades a toda una pléyade de anormales en todos los aspectos morales, psicológicos y materiales de esta palabra, cuya clasificación forzosamente corresponde a los sanguinarios dirigentes de las monstruosidades antes enumeradas (Restrepo, 1937, p. 98).

No sorprende entonces que mostrara sin ambages su evidente inclinación por el levantamiento franquista en otro de sus textos políticos más conocidos y difundidos por todo el territorio colombiano, el cual cita José Ángel Hernández García (2006): 
[Hay] todavía hombres de bien, tan cándidos o tan mal informados, que creen que en esta lucha gigantesca que se desarrolla en España, el llamado gobierno de Madrid, de Valencia o de Barcelona, representa la legalidad y la voluntad del pueblo y que Franco no es más que un vulgar caudillo alzado en armas, al impulso de sus ambiciones [...]. Lo que importa es que tengamos clara la idea sobre la licitud, necesidad y hasta obligación del levantamiento en armas por parte del pueblo y del ejército de España contra los hombres, que adueñados de poder, habían perdido el control de la máquina gubernamental y llevaban a España, a la carrera, a un rápido y definitivo desastre (p. 50).

Aunque con el tiempo Restrepo moderó el tono de sus posturas políticas y, como se vio en el episodio de La mala hora, incluso intervino en favor de García Márquez y los potenciales escritores sometidos al escrutinio del INLE en aquel entonces, no es posible aminorar el impacto que su mediación política y moral jugó en la panorámica cultural colombiana y en la historia de su literatura, a lo menos en la naciente y encumbrada obra de García Márquez.

\section{Félix Restrepo y el franquismo}

Además de director de la Academia Colombiana de la Lengua (1955-1965), Restrepo fue rector de la Pontificia Universidad Javeriana, socio de la Academia Colombiana de Historia y miembro de la Academia Colombiana de Jurisprudencia. Desde su fundación en 1942, colaboró también con el Instituto Caro y Cuervo con la misión de continuar el Diccionario de construcción y régimen de la lengua castellana de Rufino José Cuervo. Entre muchas de sus ocupaciones y nombramientos, en agosto de 1960, la Asociación de Escritores y Artistas de Colombia lo designó como presidente honorario de su entidad artística (Cacua Prada, 1997, p. 251). De acuerdo con Restrepo, eran las Academias las encargadas de vigilar el cuidado de la lengua nacional desplegada en la radio, el cine, la prensa, la televisión y, particularmente, a través de la literatura. Esta supervisión guarda un sesgo ideológico muy parecido al puesto en práctica por los censores del franquismo a la literatura latinoamericana, con la excusa de extender geográficamente sus posibilidades de lectura. Así, Restrepo refiere a la presumida existencia de un "castellano universal", de "construcción castiza" y de "giro castellano", esto es, a un español sin más neologismos que los "necesarios" y el uso exclusivo de aquellos "modismos comúnmente aceptados". Por lo que no sorprende su intervención en las líneas y título de la novela, en favor de la "conservación del idioma" y en cruzada constante contra el "desdecir de la nobleza de la lengua", que no es otra cosa que la ocultación de las variantes regionales colombianas o, en sus propias palabras, las hablas "del pueblo hablando a su manera": 
Todo libro, al revés de los periódicos, aspira a ser leído fuera de la tierra que se edita. Todo libro por eso mismo debe estar escrito en castellano universal, con la única excepción de aquellas novelas de costumbres que en sus diálogos introducen al pueblo hablando a su manera. Claro está que en el léxico no pueden evitarse las palabras de la flora y fauna local y otros neologismos necesarios; pero esto es lo de menos cuando se trata de conservar el idioma. Lo principal es la morfología tradicional, la construcción castiza, el uso de los modismos comúnmente aceptados, en una palabra, el giro castellano. $Y$ en este terreno, nuestras academias pueden hacer una magnífica obra, estimulando a las editoriales para que no acepten ni pongan en circulación libros que desdigan de la nobleza de nuestra lengua (Garrido, Valadés y Zerón-Medina, 2010, p. 162).

Como se dijo anteriormente, además de su larga y reconocida trayectoria como baluarte de la custodia de la lengua, Félix Restrepo es conocido por su conformidad y cercanía con el régimen franquista durante las primeras décadas del siglo xx. Restrepo fue una activa voz en los debates que rondaron el tema de la Guerra Civil a finales de la década de los treinta en Colombia. Por ese entonces, Restrepo no escatimó sus esfuerzos por producir textos que expresaran su inclinación política en favor del bando nacionalista. Desde la Revista Javeriana de la que fuera director, publicó varios artículos donde aprobaba el avance de las tropas franquistas y su repulsión por las acciones de las fuerzas republicanas. Luego, en 1937, publicó España mártir, una crónica de los desmanes de las milicias republicanas contra los nacionalistas luego de las elecciones de 1936. Por más señas, ya por 1956, aunque se había desmarcado de la contienda política, el gobierno de Franco lo condecoró con el título de Comendador de Número de la Orden Isabel la Católica por su labor erudita y compromiso con la preservación de la lengua española (Cacua Prada, 1997, p. 227).

Estas resonancias políticas entre el discurso hispanista y el régimen franquista permearon la agenda cultural y pedagógica colombiana, a manos de Félix Restrepo. Asimismo, el correlato del proyecto económico corporativista, que acompañó la agencia cultural y política del jesuita, supuso que hablar de fieles católicos y hablantes obedientes eran dos y una misma cosa. El proyecto corporativista de Restrepo, en tanto confesional y predestinado para el bien común, constituye una justificación moral para la subordinación de ciertos ciudadanos, cuyas "formas de hablar" se corresponden con un orden social esencial al bienestar de toda la ciudadanía (Chaves-O’Flynn, 2019, p. 148). Esta lógica no está muy lejos de explicar también la velada jerarquización de las variantes castellanas, reafirmando la superioridad de la variante peninsular por encima de las variedades americanas. 
A la luz de estas ideas, es posible percatarse del influjo político que la Academia Colombiana de la Lengua, en cabeza de Félix Restrepo, la inle y las políticas de censura franquistas impusieron ideológicamente sobre las letras colombianas. En ese sentido, en la alteración del título de la novela de García Márquez reposa un episodio glotopolítico vinculado al corporativismo confesional, a la exaltación del fascismo colombiano y al autoritarismo lingüístico del discurso hispanista, que en ningún caso puede resultarnos trivial. Antes bien, se trata de un incidente de naturaleza política que traspasa todas las esferas del dominio nacional y cultural colombiano, y que adquiere como escenario la primera novela colombiana que, casualmente, ficcionaliza el intenso período de pugna bipartidista en Colombia conocido como la Violencia.

Curiosamente, uno de los personajes principales de La mala hora es también un sacerdote católico, el Padre Ángel, cuya misión es "reconstruir la moral" del pueblo (García Márquez, 2010, p. 48) a través de la censura de películas, de las que selecciona solo aquellas que resultan "buenas para todos" (p. 23), y la consumación de sacramentos como el matrimonio y la confesión entre los aldeanos más pecaminosos. Entre tanto, el Padre Ángel desatiende el sangriento conflicto político que tiene lugar en el pueblo y se muestra inclinado a favorecer en sus decisiones a quienes controlan el poder y las leyes del mismo. Visto así, Félix Restrepo no pudo escoger un texto más oportuno para poner en juego su capacidad de intervención glotopolítica. El pasaje de La mala hora articula mecanismos de sometimiento ciudadano, a través de instituciones especializadas como la Iglesia, la Academia de la Lengua, la INLE, la escuela, los medios de comunicación y la literatura, que operan en favor de ideologías lingüísticas, que a su vez promueven la reproducción de un orden social específico e inmutable, en beneficio de quienes ostentan el poder. En ese sentido el episodio de La mala hora es un suceso que amerita ser revisado desde una perspectiva crítica que repare en el cruce entre categorías de lengua, contexto político, autoridad y dominio (Del Valle, 2007, p. 127). Es decir, es un hecho que exige de nuestra parte esta lectura glotopolítica, pues es antecedente de procesos de dominio lingüístico posteriores a él. De otra forma, esta ocurrencia seguirá listada en la historia cultural de Colombia como lo ha venido siendo hasta el momento, un incidente insignificante, puesto al margen de las lecturas críticas que se han realizado de la novela, y sin contenido político relevante. Gesto que pasa por alto el "doblaje" en "lengua de indio" de la novela colombiana al "más puro dialecto de Madrid", y en esa medida obedece, de alguna manera, a la sumisión impuesta a los hablantes desde el corazón de la RAE y la INLE. 


\section{Conclusiones}

La corrección es una forma de poder. Y en el forcejeo editorial de La mala hora, entre la Academia Colombiana de la Lengua, los censores españoles del inLE y García Márquez acecha un aparato de dominación lingüística que no debe pasarse por alto. Tanto bajo la censura, presumidamente ligera, del título y los "brochazos obscenos" como bajo el "doblaje al español madrileño" del texto original se arraiga una red de relaciones de poder y subordinación entre los hablantes de la lengua española que recrea las relaciones de antaño entre España y sus excolonias, solo que esta vez desde un escenario aparentemente apolítico: la lengua. Nada más lejano de la verdad, pues un vistazo de soslayo al contexto sociopolítico del momento enseña que la autoridad investida por Félix Restrepo y los censores de la INLE no es, ni más ni menos, que la del franquismo español, inoculada en la tradición literaria colombiana a través de su indiscutida custodia sobre la lengua. Se trata, en últimas, de una censura de corte fascista que hizo estragos en la literatura colombiana y que ha pasado por la historia de nuestras letras como un inofensivo y preocupado gesto por evitar un "desdecir de la nobleza de la lengua" por parte de sus más implacables y arbitrarios guardianes. Imprecisión que ha ocultado por años las contiendas políticas, exclusiones, prácticas autoritarias y subordinaciones impuestas sobre los escritores, lectores y hablantes de una "lengua compartida", por voluntades institucionales y estatales que no se compadecen con la diversidad lingüística por la que dicen propender. Nos queda un sinsabor chocante que quizás pueda expresar mejor la voz del peluquero del pueblo en reproche al Juez Arcadio en las líneas de La mala hora: "Antes de ustedes, este era un pueblo de mierda, como todos, pero ahora es el peor de todos” (García Márquez, 2010, p. 176).

\section{Referencias bibliográficas}

Ayala Diago, C. A. (2011). Trazos y trozos sobre el uso y abuso de la Guerra Civil Española en Colombia. Anuario Colombiano de Historia Social y de la Cultura 38 (2), pp. 111-152. Recuperado de https://revistas.unal.edu.co/index.php/achsc/article/view/28086 [19.05.2021].

Cabello Pino M. (2019). Las ideas de García Márquez sobre el diccionario y el léxico del español en Notas de prensa 1980-1984. Analecta Malacitana 40, pp. 93-126.

Cabello Pino, M. (2020). Las ideas de García Márquez sobre el diccionario y el léxico del español: análisis del "prólogo" al Clave, Diccionario de uso del español actual. Lingüística y Literatura 41 (77), pp. 444-463. DOI: https://doi.org/10.17533/udea.lyl.n77a20 
Cacua Prada, A. (1997). Félix Restrepo, S. J. Santafé de Bogotá: Instituto Caro y Cuervo.

Chaves-O’Flynn, C. (2019). Lengua, política y moral: intervenciones glotopolíticas de Félix Restrepo, S. J. Durante el siglo xx en Colombia. Glottopol: revue de sociolinguistique 32, pp. 133-150. Recuperado de http://glottopol.univ-rouen.fr/telecharger/numero 32/gpl32 06chaves.pdf [19.05.2021].

Chuliá, E. (1999) La Ley de Prensa de 1966: la explicación de un cambio institucional arriesgado y de sus efectos virtuosos. Historia y politica: Ideas, procesos y movimientos sociales 2, pp. 197-220.

De Arnoux, E. N. y Del Valle, J. (2010). Las representaciones ideológicas del lenguaje: discurso glotopolítico y panhispanismo. Spanish in Context 7 (1), pp. 1-24.

Del Valle, J. (2007). Glotopolítica, ideología y discurso: categorías para el estudio del estatus simbólico del español. En La lengua, ̇̇patria común?: ideas e ideologías del español. Frankfurt y Madrid: Vervuert-Iberoamericana [versión Kindle].

Figueroa Salamanca, H., y Tuta Alarcón, C. (2005). El estado corporativo colombiano: una propuesta de derechas. 1930-1953. Anuario Colombiano de Historia Social y de la Cultura 32, pp. 99-148. Recuperado de https://revistas.unal.edu.co/index.php/achsc/article/view/8191/8835 [19.05.2021].

Gaitán-Bohórquez, J., y Malagón-Pinzón, M. (2009). Fascismo y autoritarismo en Colombia. Vniversitas 58 (118), pp. 293-316. Recuperado de https://revistas.javeriana.edu.co/index.php/vnijuri/ article/view/14525 [19.05.2021].

García Márquez, G. (1966). La mala hora. Altos, México: Ediciones Era.

García Márquez, G. (2002). Vivir para contarla. Nueva York: Alfred A. Knopf.

García Márquez, G. (2007). Cien años de soledad. Madrid: Alfaguara-RAE.

García Márquez, G. (2010). La mala hora. Nueva York: Vintage Español-Random House.

Garrido, F., Valadés, D., y Zerón-Medina, F. (2010). Orígenes de la Asociación de Academias de la Lengua Española. México, D.F.: Academia Mexicana de la Lengua.

Henríquez de Hernández, C. (1989). El sagrado corazón en la historia de Colombia. Revista de la Universidad Nacional 22, pp. 80-88. Recuperado de https://revistas.unal.edu.co/index.php/revistaun/ article/view/12112 [19.05.2021].

Hernández García, J. Á. (2006). La Guerra Civil Española y Colombia: influencia del principal conflicto de entreguerras en Colombia. Bogotá: Universidad de la Sabana.

Jaramilo, F. (2012). Sobre La mala hora. Memorabilia GGM. Recuperado de https://memorabiliaggm. blogspot.com/2012/09/memorabilia-ggm-606-v.html [19.05.2021].

Mesa, R. (2005). La complicada evolución de la libertad de prensa en España durante el siglo xx. Apuntes para su estudio. Espéculo 30. Recuperado de https://webs.ucm.es/info/especulo/numero30/ liprensa.html [19.05.2021]. 
Restrepo, F. (1937). España mártir. Bogotá: Ediciones de la Revista javeriana.

Sánchez García, R. y Jiménez Mañas, M. (2012). Botella al mar para el dios de las palabras. Reflexiones de García Márquez sobre gramática y ortografía. Álabe 6. DOI: http://dx.doi.org/10.15645/ Alabe.2012.6.7

Santana-Acuña, Á. (2020). Ascent to Glory. New York: Columbia University Press. 